\title{
The Mental Protection System for Protective Behaviors: The Social Brain and the Mental Immune System
}

\author{
Dingyu Chung \\ Utica, Michigan, USA \\ Email: dy_chung@yahoo.com
}

How to cite this paper: Chung, D. (2018) The Mental Protection System for Protective Behaviors: The Social Brain and the Mental Immune System. Journal of Behavioral and Brain Science, 8, 31-55. https://doi.org/10.4236/jbbs.2018.81003

Received: December 1, 2017

Accepted: January 9, 2018

Published: January 12, 2018

Copyright $\odot 2018$ by author and Scientific Research Publishing Inc. This work is licensed under the Creative Commons Attribution International License (CC BY 4.0).

http://creativecommons.org/licenses/by/4.0/

Open Access

\begin{abstract}
The physical protection system of the body consists of the protective organs for vulnerable body parts-functions and the protective countermeasures against invaders (pathogens), but to survive, the body also requires the protective social groups for vulnerable social members-functions and the protective instinctive mental countermeasures against adversities such as hardship, danger, and unfamiliarity-uncertainty. As a result, this paper proposes that the mental protection system of the body consists of the social brain to set up the protective social groups for vulnerable social members-functions and the mental immune system to produce the protective mental countermeasures against adversities. This paper proposes that from the social brain, the protective social groups include alliance group for vulnerable individuals, kinshipfriendship group for vulnerable children, interdependent specialists group for vulnerable pregnant females, territorial group for social boundary, connective group for social connection, and competitive group for social competition. From the mental immune system, the mental protective countermeasures include comforter against hardship, hyperactivity against danger, phobia against unfamiliarity-uncertainty, and rationality against unfamiliarity-uncertainty. The overactive mental immune system causes mental allergies and auto immune diseases as personality-mental disorders against ubiquitous harmful and harmless perceived adversities, correlating to physical allergies and auto immune diseases against ubiquitous harmful and harmless detected invaders. The mental protection system also produces personality traits, social moralities, social organizations, social systems, religions, and cultures as described in this paper. The mental protective system is the source of protective behaviors.
\end{abstract}

\section{Keywords}

Mental Protection System, Social Brain, Mental Immune System, Big Five 
Personality Traits, Social System Traits, Personality Disorders, Psychotherapy, Religions, Western Culture, Eastern Culture, Protective Behaviors

\section{Introduction}

The physical protection system of the body includes the integumentary system to set up protective organs for vulnerable body parts-functions and the immune system to produce countermeasures against harmful invaders (pathogens). The functions of the integumentary system consisting of the skin, hair, nails, glands, and nerves are to act as a barrier to protect the vulnerable body parts from the outside world, to retain body fluids, to protect against disease, to eliminate waste products, and to regulate body temperature. Different protective organs protect different vulnerable body parts-functions. The vulnerable body parts-functions reside within the protective organs set up by the integumentary system. The immune system is a network of cells, tissues, and organs that work together to provide countermeasures against harmful invaders. Different immune subsystems provide different countermeasures against different harmful invaders. The balanced immune system has the immune system regulators to balance the activities of the immune system. For example, some white cells activate immune responses, whereas others are the immune system regulators that function in the opposite direction by constraining immune responses. As the highly imbalanced immune system without the proper immune system regulators, the overactive immune system causes allergies and auto immune diseases as physical disorders against ubiquitous harmful and harmless detected invaders.

The integumentary system sets up protective organs to protect the body physically and individually. However, the body cannot survive alone without the protection of protective social groups, so the body requires both protective organs and protective social groups to survive. The body also faces various adversities, such as hardship, danger, and unfamiliarity-uncertainty. To survive, the body needs the protective mental countermeasures against such adversities quickly and instinctively, so the body needs both the physical countermeasures against invaders and the mental countermeasures against adversities. As a result, this paper proposes that the mental protection system of the body consists of the social brain [1] [2] [3] [4] to set up the protective social groups [5] [6] for the vulnerable social members-functions and the mental immune system [6] [7] to produce the protective mental countermeasures against adversities. The body requires not only the physical protection system but also the mental protection system to survive.

This paper proposes that from the social brain, the protective social groups include protective alliance group for vulnerable individuals, protective kinship-friendship group for vulnerable children, protective interdependent specialists group for vulnerable pregnant females, protective territorial group for 
social boundary, protective connective group for social connection, and protective competitive group for social competition. From the mental immune system, the mental protective countermeasures include comforter against hardship, hyperactivity against danger, phobia against unfamiliarity-uncertainty, and rationality against unfamiliarity-uncertainty. In the social brain, the different protective social groups set up by the social brain protect different vulnerable social members-functions. The vulnerable social members-functions reside within the protective social groups set up by the social brain. In the mental immune system, the different mental immune subsystems provide the different countermeasures against different adversities. The balanced mental immune system has the mental immune system regulators to balance the activities of the mental immune system. As the highly imbalanced mental immune system without the proper mental immune system regulators, the overactive mental immune system causes mental allergies and auto immune diseases as personality-mental disorders against ubiquitous harmful and harmless perceived adversities. Therefore, the physical protection system correlates to the mental protection system.

The mental protection system also produces personality traits, social moralities, social organizations, social systems, religions, and cultures as described in this paper. The mental protective system is the source of protective behaviors. Section 2 describes the social brain to set up alliance group, kinship-friendship group, interdependent specialists group, territorial group, connective group, and competitive group. It also describes social moralities, social organizations, and cultures. Section 3 describes the mental immune system to produce the protective mental countermeasures consisting of comforter, hyperactivity, phobia, and rationality. It also describes personality-mental disorders as the overactive mental immune system, the religious mental immune system, the drug addiction disorders, psychiatric epidemiology, the therapy for the personality-mental disorders, and the correlations of the big five mental protection traits from the mental protective system, the big five social system traits [6], and the big five personality traits [8].

\section{The Social Brain}

The social brain [1] [2] [3] [4] is the network of brain regions that are involved in understanding others. We are biologically hard-wired for interacting with others. The social brain is located mainly in the neocortex in the outmost layer of the brain. The neocortex is much larger in humans as compared to other primates and mammals of similar size. The social brain also involves the neurotransmitter/hormone system to provide a psychopharmacological platform for the cognitive component.

The social brain in the mental protection system of the body sets up the protective social group to protect vulnerable social members-functions for the bodies [5] [6], correlating to the integumentary system to set up the protective organs to protect vulnerable body parts-functions for the body. The social brain 
consists of the social member protection system and the social function protection system. The social member protection system consists of individualistic sociality for alliance group [1] [2] to protect vulnerable individuals against predation, collectivistic sociality for kinship-friendship group [9] to protect vulnerable children against neglect, interdependent sociality for interdependent specialists group [10] [11] to protect vulnerable pregnant females against neglect. The social function protection system consists of territorial worldview for territorial group to protect social boundary between ingroup and outgroup, connective worldview for connective group to protect social connection, and competitive worldview for competitive group to protect social competition. The social brain can also produce personality traits as in the big five personality traits [8], which consist of extraversion (assertive, energetic, talkative), agreeableness (cooperative, good-natured, trusting), neuroticism (easily upset, maladjusted, not calm), conscientiousness (dependable, orderly, responsible), and openness to experience (imaginative, independent-minded, intellectual) as well as the opposites including introversion, disagreeableness, calmness, impulsiveness, and closeness to experience. The social brain and personality traits are listed in Table 1, and are described in the following subsections.

\subsection{Individualistic Sociality for Protective Alliance Group}

As a part of the social brain, individualistic sociality protects vulnerable individuals against predation by forming alliance group [1] [2] whose relationships depend on reciprocal benefit of individuals rather than commitment to a social group. The base of individualistic sociality is extensive and complex socialization. A vulnerable individual against predation is motivated to form as many alliances as possible by socialization, resulting in extensive socialization. However, for primates, the formation of a stable alliance group requires complex socialization to settle the stress within the alliance group, resulting in complex socialization. For primates, the brain size for individualistic sociality is proportional to the group size and the complexity of socialization [1] [2]. According to Dunbar, the proper group size based on the human brain size is around 150 [12].

The brain for individualistic sociality deals with extensive socialization and complex socialization separately. Extensive socialization requires the rewarding neurotransmitters such as endorphins [1] [2] to reward socialization with

Table 1. The social brain and personality traits.

\begin{tabular}{|c|c|c|c|c|}
\hline Mental protection & Social brain & Protective social group & $\begin{array}{l}\text { Protected social } \\
\text { members-function }\end{array}$ & Personality trait \\
\hline \multirow{3}{*}{$\begin{array}{l}\text { Social member } \\
\text { protection }\end{array}$} & Individualistic sociality & Alliance group & Vulnerable individuals & Extraversion \\
\hline & Collectivistic sociality & Kinship-friendship group & Vulnerable children & Introversion \\
\hline & Interdependent sociality & Interdependent specialists group & Vulnerable pregnant females & Interdependent \\
\hline \multirow{2}{*}{$\begin{array}{l}\text { Social function } \\
\text { protection }\end{array}$} & Territorial worldview & Territorial group & Social boundary & Territoriality \\
\hline & Competitive worldview & Competitive group & Social competition & Disagreeableness \\
\hline
\end{tabular}


individuals including strangers and even opponents, while complex socialization requires proper connections among the social brain cells, such as the connection between language-related processing in the left hemisphere and emotion-related processing in the right hemisphere, to facilitate proper complex socialization. The defect in the complex socialization leads to autism that does not have proper cell connections to engage in complex socialization [13]. Autistic people have poor socialization skills to form alliances. The specific defect in the complex socialization leads to Williams Syndrome that has the excellent connection between the recognition of language and the recognition of emotion, but does not have good connections among other important social brain cells. The people with Williams Syndrome are excellent in the initial socialization with all people, but are difficult to keep complex relationships with alliances.

In terms of personality trait, extensive and complex socialization lead to extraversion personality trait that likes and is skillful in socialization with alliances whose relationships depend on reciprocal benefit rather than commitment. Extravert people draw pleasure from making alliances as the result of endorphins released.

\subsection{Collectivistic Sociality for Protective Kinship-Friendship Group}

As a part of the social brain, collectivistic sociality protects vulnerable children against neglect by forming kinship-friendship group [14] whose relationships depend on commitment to a social group rather than reciprocal benefit of individuals. The base of collectivistic sociality is durable and complex commitment. A caregiver for a vulnerable child is motivated to form durable kinship-friendship group to take care of the vulnerable child as long as possible by commitment, resulting in durable commitment. The original kinship-friendship group was derived from bi-parental care. The cognitive mechanisms necessary for pair bonding and coordinated bi-parental care are generalizes to non-reproductive individuals to form kinship-friendship group. For non-primate vertebrates, such as birds, the intensive care for the fast-growing infant birds is important, so collectivistic sociality for durable kinship-friendship such as pair-bonding between parents is important to improve the survival of infants. The formation of a durable kinship-friendship group requires complex commitment to resolve the stress and the coordination problems within the kinship-friendship group, resulting in complex commitment. For non-primate vertebrates, the brain size for collectivistic sociality is proportional to the duration and complexity of commitment [9].

The brain for collectivistic sociality deals with durable commitment and and complex commitment separately. Durable commitment requires the bonding neurotransmitters such as oxytocin [15] to reward committed bonding with kin and friends and the strong emotion from the amygdala, while complex commitment requires proper connections among the social brain cells, such as the 
precise recognition of kin and friends and the precise coordination with kin and friends, to facilitate proper complex commitment. The hypoactive commitment leads to poor parental care and poor kinship-friendship group.

In terms of personality trait, durable and complex commitment leads to introversion personality trait that likes and is skillful in commitment with kinship-friendship group whose relationships depend on commitment rather than reciprocal benefit. The commitment to a group instead of group size is the main concern of introvert people. Introvert people draw pleasure from making kin and friends as the result of oxytocin released.

\subsection{Interdependent Sociality for Protective Interdependent Specialists Group}

As a part of the social brain, interdependent sociality protects vulnerable pregnant females against neglect by forming interdependent specialists group whose relationships depend on interdependent specialties for the division of labor. In animals, one example of interdependent specialists group for the division of labor is the social group of bees which have the vulnerable pregnant queen bee whose specialty is reproduction and who requires the care of infertile female worker bees as procurement specialists that require the queen bee to reproduce. As a result, bees form the interdependent specialists group consisting of reproductive queen bees, infertile female worker bees, and fertile male drones. Interdependent sociality is eusociality [10] as the highest level of organization of animal sociality. Ants, bees, and termites are eusocial animals. Eusocial animals dominate the earth in terms of the total mass of eusocial animals to indicate the vastly superior eusocial organization.

Human is a species of eusocial ape [16]. During human evolution, the emergence of vulnerable pregnant females was derived from bipedalism [17] about four million years ago [18] in the mixed habitat of grassy woodland with patches of denser forest of tall trees. The primitive feet from the original bipedalism were still suitable for climbing trees, and not suitable to run fast on the ground especially for pregnant women and small children. In the mixed habitat of grassy woodland with patches of denser forest of tall trees, pregnant women took care of children, and searched foods in the forest area of tall trees as safe home where they could quickly escape to tall trees by climbing, whereas other people explored grassy woodland area to search for foods. Older women evolved into infertile women to help pregnant women and child care in the forest of tall trees. All of them shared foods. As result, early human ancestors formed the interdependent specialists group consisting of fertile homemaker-forager, infertile homemaker-forager, and fertile explorer-forager in the mixed habitat of grassy woodland with patches of denser forest of tall trees. The interdependent specialists group of late human ancestors with the feet suitable for running instead of climbing consisted of fertile homemaker-gatherer, infertile homemaker-gatherer, and fertile explorer-hunter in the open habitat [17]. 
Such interdependent specialists group produced theory of mind (mind-reading) that recognizes that the others exist to think for themselves. Theory of mind is derived from theory of specialty (specialty-reading) in interdependent specialists group where each specialist has its own specialty of work and work plan. In theory of specialist, each specialist must recognize that each specialist has its own specialty different from the specialties of other specialists, and each specialist has its own work plan distinctively different from the work plans of other specialists. To work together interdependently, all specialists must have theory of specialist in order to avoid overlapping unproductively and dangerously each other's work. Theory of specialty turned into theory of mind where specialty was replaced by the mind of each person. In theory of generality, each generalist does not need to distinctively recognize the types of work and work plans of other generalists, because they are not distinctively different. As a result, theory of generality does not turn into theory of mind.

Theory of mind is the base of mind-reading mentalization [11] which is the base of interdependent sociality. Interdependence required gentle temperament toward one another for interdependent relationship. Gentle temperament was shown in the disappearance of sharp canine teeth in early human ancestors as the only apes without sharp canine teeth for internal fighting. Initially, the task was relatively simple for the interdependent specialists group, and mind-reading capability did not need large extra brain size, so the brain size of early human ancestors was similar to the brain size of other apes. As the rapid environment changes due to rapid fluctuating temperature changes, the task became increasingly complex for tools, fire, and social interactions to adapt to changing environments. Such complex task required complex mentalization for coordination and conflict resolution in interdependent specialists group, resulting in the rapid increase in the neocortex brain size for interdependent sociality. The neocortex brain size for interdependent sociality is proportional to the group size and the complexity of mentalization. The damages in the frontal, insular, and temporal cortex cause the problems to understand other people's intentions and beliefs (mentalization) [19]. In terms of personality trait, mild and complex mentalization leads to interdependence personality trait that is gentle and skillful in the division of labor.

\subsection{Territorial, Connective, and Competitive World Views for Social Boundary, Connection, and Competition}

As a part of the social brain, territorial worldview protects vulnerable social boundary between ingroup and outgroup by forming territorial group whose relationships among individuals depend on ingroup or outgroup. In ingroup, individuals have similar interests and outlooks, and produce the feeling of connection among them [20]. Individuals in outgroup outside the boundary of one's own group are different in interests and outlook, and produce the feeling of zero-sum competition toward outgroup. The proper behavior as morality toward 
ingroup is connection, whereas the proper behavior toward outgroup is zerosum competition [21]. Such ingroup-outgroup boundary instinct appears even in infants at few months old [22]. As shown in the Infant Cognition Center at Yale University, babies prefer the objects (such as dolls) as ingroup objects that have similarities with the babies rather than the objects as outgroup objects that do not have similarities with the babies. Babies also prefer the objects with helpful behavior to the objects with bully behavior. However, babies prefer the doll that bullies another doll that is not like the babies. In other words, even though babies dislike the individuals who harm other individuals, babies prefer the individuals who harm outgroup individuals that are not like the babies. The zerosum competitive attitude toward outgroup is instinctive. Such ingroup-outgroup boundary instinct enhances the survival of social group against invading outgroup during evolution [23].

Ingroup-outgroup boundary instinct is possible if the differentiation and social boundary between ingroup and outgroup are clear. Without the clear differentiation and social boundary between ingroup and outgroup, all encountering individuals are potentially the individuals in ingroup, or are potentially the individuals in outgroup. If all encountering individuals are potentially in ingroup, ingroup-outgroup boundary instinct turns into connective instinct without distinct social boundary. If all encountering individuals are potentially in outgroup, ingroup-outgroup boundary instinct turns into competitive instinct without distinct social boundary. As a result, the three worldviews are territorial worldview to protect social boundary, connective worldview to protect social connection, competitive worldview to protect social competition. As described in the previous papers [5] [6], male chimpanzees, the nomadic society, and Western culture favor competitive worldview, while female bonobos, the agricultural society, and Eastern culture favor connective worldview. In terms of personality traits, territorial worldview has territoriality personality trait, connective worldview has agreeableness personality trait, and competitive worldview has disagreeableness personality trait.

\subsection{Social Moralities, Social Organizations, and Cultures}

The social brain for social member protection system consists of individualistic, collectivistic, and interdependent socialities, while the social brain for social function protection system consists of connective, competitive, and territorial worldviews. The combination of social member protection system and social function protection system results in nine different worldview-sociality systems, including the connective individualistic, competitive individualistic, territorial individualistic, connective collectivistic, competitive collectivistic, territorial collectivistic, connective interdependent, competitive interdependent, and territorial interdependent systems. Each system has its morality as the most appropriate behavior, its suitable social organization, and its suitable cultures [5] [6].

The morality for individualistic sociality is individual achievement for all in- 
dividuals, so the morality for the connective individualistic system is connective individual achievement, the morality for the competitive individualistic system is zero-sum competitive individual achievement, and the morality for territorial individualistic system is territorial individual achievement. The morality for collectivistic sociality is common well-being to take care of all individuals, so the morality of the connective collectivistic system is connective common well-being. The morality for the competitive collectivistic system is competitive common well-being, and the morality for territorial collectivistic system is territorial common well-being. The morality for interdependent sociality is interdependent specialty, so the morality for the connective interdependent is connective interdependent specialty, the morality of the competitive interdependent system is competitive interdependent specialty, and the morality of territorial interdependent system is territorial interdependent specialty.

As described in the previous paper [5], each type of brain with a specific morality can be suitable to a specific social organization. The connective individualistic system with connective individual achievement is suitable for individualistic meritocracy based on merit (hierarchical achievements) instead of zero-sum competition (winner-takes-all). The competitive individualistic system with competitive individual achievement is suitable for individualistic democracy based on zero-sum competition among individuals. Individualistic democracy is liberal democracy. The territorial individualistic system with territorial individual achievement is suitable for individualistic protectionism based on the protection of individual right. Collectivistic sociality concerns about common wellbeing for all people, so collectivistic sociality is basically socialistic. As a result, the connective collectivistic system with connective common well-being is suitable for socialistic meritocracy, the competitive collectivistic system with competitive common well-being is suitable for socialistic democracy, and the territorial collectivistic system with territorial common well-being is suitable for socialistic protectionism. The connective interdependent system with connective interdependent specialty is suitable for interdependent meritocracy, the competitive interdependent system with competitive interdependent specialty is suitable for interdependent democracy, and the territorial interdependent system with territorial interdependent specialty is suitable for interdependent protectionism. The social moralities and social organizations are listed in Table 2.

In terms of cultures [5] [6], Western culture originated from the Middle East and Greece favors competitive worldview with global competitive democracy, market economy, militarized offensive foreign policy, and religions (Judaism, Islam, and Christianity). The global interdependent Western religion is Christianity with the interdependent specialists group where each believer is special and interdependent with other believers. Eastern culture originated from India and China favors connective worldview with global connective meritocracy, market economy, infrastructural foreign policy, and religions (Hinduism, Confucianism, Buddhism, and Daoism). The global interdependent Eastern religions 
Table 2. The social moralities and the social organizations in the worldview-sociality systems.

\begin{tabular}{|c|c|c|c|}
\hline & Connective & Competitive & Territorial \\
\hline Individualistic & $\begin{array}{l}\text { Connective individual achievement } \\
\text { Individualistic meritocracy }\end{array}$ & $\begin{array}{l}\text { Competitive individual achievement } \\
\text { Individualistic democracy }\end{array}$ & $\begin{array}{l}\text { Territorial individual achievement } \\
\text { Individualistic protectionism }\end{array}$ \\
\hline Collectivistic & $\begin{array}{l}\text { Connective common well-being } \\
\text { Socialistic meritocracy }\end{array}$ & $\begin{array}{l}\text { Competitive common well-being } \\
\text { Socialistic democracy }\end{array}$ & $\begin{array}{l}\text { Territorial common well-being } \\
\text { Socialistic protectionism }\end{array}$ \\
\hline Interdependent & $\begin{array}{l}\text { Connective interdependent Specialty } \\
\text { Interdependent meritocracy }\end{array}$ & $\begin{array}{l}\text { Competitive interdependent specialty } \\
\text { Interdependent democracy }\end{array}$ & $\begin{array}{l}\text { Territorial interdependent specialty } \\
\text { Interdependent protectionism }\end{array}$ \\
\hline
\end{tabular}

are Daoism and Buddhism with interdependent relationship among the believers.

The perceptions of competitive Western culture and connective Eastern culture are completely different as proposed by Nisbett and Yuki, [24] [25]. The perception of connective worldview focuses in connective relationships among connective individuals to produce "relationship perception", whereas the perception of competitive worldview focuses in separate identities among competitive individuals to produce "identity perception". With connective worldview, the Easterners with relationship perception perceive a world of continuous and connected objects with relationships, whereas with competitive worldview, the Westerners with identity perception perceive a world of discrete and unconnected objects in categories based on similarity and difference. A typical test is the pairing of monkey, panda, and banana. The Easterners favors the pairing of monkey and banana based on the relationship between monkey and banana (monkey eats banana), while the Westerners favors the pairing of monkey and panda based on the category of monkey and panda (monkey and panda are primates).

\section{The Mental Immune System}

The physical immune system is a physical protective system against pathogens (harmful invaders), whereas the mental immune system [6] is a mental protective system against adversities such as hardship, danger, and unfamiliarity-uncertainty. The overactive immune system without proper immune system regulators produces physical allergies as physical disorders, whereas the overactive mental immune system without proper mental immune system regulators [6] produces mental allergies as personality-mental disorders. Therefore, the physical immune system correlates to the mental immune system. The mental immune system and the physical immune system interact. For example, excessive chronic production of inflammatory cytokines from the overactive physical immune system has been linked to depression resulted from the overactive mental immune system [7].

The mental immune system involves both the brain cell network and the endocrine system. The mental immune system against adversity consists of the mental countermeasure to overcome adversity and the persistent mental focus to 
focus in adversity. The response of the mental countermeasure is fast, whereas the response of the mental focus is slow. The mental countermeasure-focus is the mental immune system against adversity. The mental countermeasure can be the emotional countermeasure or the rational countermeasure. The mental focus associated with the emotional countermeasure is emotional stress, while the mental focus associated with the rational countermeasure is emotionless indecision. One example of the countermeasure-focus systems is the hyperactivity-stress axis as the sympathetic-adrenomedullary (SAM) axis-hypothalamic-pituitary-adrenal (HPA) axis against danger as the adversity. The main neurotransmitters from the SAM-HPA are adrenaline-cortisol. This paper proposes that the mental immune system includes the four axes consisting of the stress-comforter axis against hardship to maintain durability, the hyperactivity-stress axis against danger to maintain existence, the phobia-stress axis against unfamiliarity-uncertainty to maintain tradition, and the phobiarationality-indecision axis against unfamiliarity-uncertainty to maintain adaptability.

In the balanced mental immune system, the mental countermeasure is balanced by the mental immune system regulator [7], in the same way as the countermeasure in the immune system is balanced by the immune system regulator that constrains the activity of the countermeasure. In the inherited highly imbalanced mental immune system without the proper mental immune system regulator, excessive adversity and mental countermeasure generate overactive stress-countermeasure as the overactive mental immune system, resulting in mental allergies and mental autoimmune disorders as personality-mental disorders against ubiquitous perceived adversity, in the same way as that the overactive immune system results in physical allergies and physical autoimmune diseases against ubiquitous detected invaders, harmful and harmless.

Personality disorders in the DSM-5 (the Diagnostic and Statistical Manual of Mental Disorders, Fifth Edition) [26] are divided into odd-eccentric cluster (schizotypal, paranoid, and schizoid), dramatic-impulsive cluster (histrionic, antisocial, borderline, and narcissistic), and anxious-fearful cluster (dependent, obsessive-compulsive, and avoidant). The additional cluster from the previous paper is doubtful-prying cluster (anarchic, quarrelsome, and evasive) [6]. This paper proposes that personality disorders are divided into odd-eccentric cluster from the overactive stress-comforter axis against ubiquitous perceived hardship, dramatic-impulsive cluster from the overactive hyperactivity-stress axis against ubiquitous perceived danger, fearful-anxious cluster from the overactive phobia-stress axis against ubiquitous perceived unfamiliarity-uncertainty, and doubtful-prying cluster from the overactive phobia-rationality-indecision axis against ubiquitous perceived unfamiliarity-uncertainty. The mental immune system, personality traits, and personality disorders is shown in Table 3 and the following subsections. 
Table 3. The mental immune system, personality traits, and personality disorders.

\begin{tabular}{|c|c|c|c|c|c|c|}
\hline $\begin{array}{l}\text { Mental immune } \\
\text { system }\end{array}$ & Adversity & Purpose & $\begin{array}{l}\text { Immune system } \\
\text { neurotransmitter }\end{array}$ & $\begin{array}{l}\text { Immune system } \\
\text { regulator }\end{array}$ & $\begin{array}{l}\text { Personality trait } \\
\text { balanced/imbalanced }\end{array}$ & $\begin{array}{l}\text { Personality } \\
\text { disorders }\end{array}$ \\
\hline Stress-comforter axis & Hardship & Maintain durability & Cortisol-endorphins & $\begin{array}{l}\text { Dopamine } \\
\text { antagonist }\end{array}$ & $\begin{array}{l}\text { Calmness/ } \\
\text { neuroticism }\end{array}$ & $\begin{array}{l}\text { Odd-eccentric } \\
\text { cluster }\end{array}$ \\
\hline $\begin{array}{l}\text { Hyperactivity- } \\
\text { stress axis }\end{array}$ & Danger & Maintain existence & Adrenaline-cortisol & Serotonin agonist & $\begin{array}{l}\text { Conscientiousness/ } \\
\text { impulsiveness }\end{array}$ & $\begin{array}{l}\text { Dramatic- } \\
\text { impulsive } \\
\text { cluster }\end{array}$ \\
\hline Phobia-stress axis & $\begin{array}{l}\text { Unfamiliarity- } \\
\text { uncertainty }\end{array}$ & Maintain tradition & $\begin{array}{l}\text { Adrenaline- } \\
\text { glutamate-cortisol }\end{array}$ & $\begin{array}{l}\text { Serotonin-GABA } \\
\text { agonist }\end{array}$ & $\begin{array}{l}\text { Closeness to } \\
\text { experiences }\end{array}$ & $\begin{array}{l}\text { Fearful- } \\
\text { anxious cluster }\end{array}$ \\
\hline $\begin{array}{l}\text { Phobia-rationality- } \\
\text { indecision axis }\end{array}$ & $\begin{array}{l}\text { Unfamiliarity- } \\
\text { uncertainty }\end{array}$ & $\begin{array}{l}\text { Maintain } \\
\text { adaptability }\end{array}$ & $\begin{array}{l}\text { Adrenaline- } \\
\text { glutamate }\end{array}$ & GABA agonist & $\begin{array}{l}\text { Openness to } \\
\text { experiences }\end{array}$ & $\begin{array}{l}\text { Doubtful- } \\
\text { prying cluster }\end{array}$ \\
\hline
\end{tabular}

\subsection{The Stress-Comforter Axis and Odd-Eccentric Cluster}

As serious hindrance to durable life, hardship as the adversity brings about stress to focus persistently in hardship as shown by the emergence of cortisol. The extensive stress leads to instinctive comforter as the mental countermeasure to overcome hardship as shown by the emergence of endorphins for the maintenance of durability. Comforter is manifested as the painless high while in stress for a long time as runner's high [27] while running for a long time. Runner's high allows an exhausted runner to continue running at normal speed. Comforter can be also as imaginary comforter (fantasy). Imaginary comforter as imaginary companion often occurs during childhood [28] to overcome hardship [29]. Up to two-thirds of children have imaginary companions, and some children develop entire imaginary worlds for their imaginary companions. The mental immune system against hardship is the stress-comforter axis with cortisol-endorphins.

The mental immune system regulator constraining stress-comforter (cortisol-endorphins) is dopamine (neurotransmitter for pleasure) antagonist in the prefrontal cortex. Excessive hardship and comforter in the inherited highly imbalanced system without the proper dopamine antagonist generate overactive stress-comforter as the overactive mental immune system, resulting in the mental allergy as odd-eccentric cluster for personality-mental disorders against ubiquitous perceived hardship as shown by excessive dopamine in the prefrontal cortex. In terms of neurotransmitters, the failure of constraining cortisol-endorphins (stress-comforter) by dopamine antagonist as the mental immune system regulator results in the mental allergy as odd-eccentric cluster. In terms of personality traits, the balanced stress-comforter axis results in calmness, whereas the moderately imbalanced stress-comforter axis with excessive imaginary comforter results in neuroticism.

In the overactive mental immune system, the perception in search for potential adversity is overactive to produce ubiquitous perceived adversity [30]. The emotion in response to adversity is exaggerated to produce all-or-nothing thinking without nuance in dealing with adversity. Therefore, the symptoms of 
odd-eccentric cluster are overactive imaginary comforter (fantasy), ubiquitous perceived hardship, and all-or-nothing thinking without nuance in dealing with hardship. Odd-eccentric cluster personality disorders include schizotypal, paranoid, and schizoid which can be differentiated by three personality traits as inoffensive (agreeableness trait), offensive (disagreeableness trait), and territorial (territoriality trait). For schizotypal, the overactive imaginary comforter is inoffensive (agreeableness). For paranoid, the overactive imaginary comforter is offensive (disagreeableness). For schizoid, the overactive imaginary comforter is territorial.

Overactive stress-comforter is more extreme in mental disorders than in personality disorders. In schizophrenia as a mental disorder, the extremely overactive imaginary comforter is hallucination where overactive fantasy becomes visible and audible like in a dream. During dream, the prefrontal cortex is deactivated. In schizophrenia, excessive dopamine in the prefrontal cortex overwhelms the prefrontal cortex to cause the decrease in the cognitive function of the prefrontal cortex, resulting in dream-like hallucination.

\subsection{The Hyperactivity-Stress Axis and Dramatic-Impulsive Cluster}

As catastrophe to existence of life, danger as the adversity brings about instinctive hyperactivity (the fight-or-flight response) as the mental countermeasure to overcome danger as shown by the emergence of adrenaline from the fast sympathetic-adrenomedullary (SAM) axis for the maintenance of existence. Hyperactivity is manifested as the rush of energy. The continuing focus in possible danger brings about stress as shown by the emergence of cortisol from the slow hypothalamic-pituitary-adrenal (HPA) axis. The mental immune system against danger is the hyperactivity-stress axis with adrenaline-cortisol. The mental immune system regulator is serotonin agonist. Excessive danger and hyperactivity in the inherited highly imbalanced system without proper serotonin agonist generate overactive hyperactivity-stress as the overactive mental immune system, resulting in the mental allergy and mental autoimmune disorder as dramatic-impulsive cluster for personality-mental disorder against ubiquitous perceived danger as shown by deficient serotonin [7]. In terms of neurotransmitters, the failure of constraining adrenaline-cortisol (hyperactivity-stress) by serotonin agonist as the mental immune system regulator brings about the mental allergy and mental autoimmune disorder as dramatic-impulsive cluster. In terms of personality traits, the balanced hyperactivity-stress axis results in conscientiousness, whereas the moderately imbalanced hyperactivity-stress axis with excessive hyperactivity results in impulsiveness.

The symptoms of dramatic-impulsive cluster are overactive hyperactivity, ubiquitous perceived danger, and all-or-nothing thinking without nuance in dealing with danger. Dramatic-impulsive cluster personality disorders include histrionic, antisocial, borderline, and narcissistic. For histrionic, the overactive hyperactivity is inoffensive (agreeableness). For antisocial, the overactive hyper- 
activity is offensive (disagreeableness) toward others. For borderline, the overactive hyperactivity is offensive (disagreeableness) toward self. For narcissistic, the overactive hyperactivity is territorial.

Overactive hyperactivity-stress is more extreme in mental disorders than in personality disorders. Depression mental disorder is the extreme form of borderline personality disorder. With the extreme depreciation of self, borderline and depression are mental autoimmune disorders against ubiquitous perceived danger in terms of ubiquitous perceived defects and flaws in self [30]. Bipolar disorder (manic-depression) possesses the mental allergy (manic) and the mental autoimmune disorder (depression) alternatively.

\subsection{The Phobia-Stress Axis and Fearful-Anxious Cluster}

As the deviation from familiar-certain traditional way of life, unfamiliarity-uncertainty as the adversity brings about instinctive phobia as the mental countermeasure against moving to unfamiliar-uncertain way of life to maintain familiar-certain traditional way of life as shown by the emergence of adrenaline-glutamate. (Glutamate is the active neurotransmitter in the prefrontal cortex to think about fear consciously.) Normally, familiar-certain tradition provides the reliable way to live, so the maintenance of tradition is important for survive. Phobia is manifested as a rush of extreme fear. The continuing focus in unfamiliarity- uncertainty leads to stress as shown by the emergence of cortisol. The mental immune system against unfamiliarity-uncertainty is the phobia-stress axis with adrenaline-glutamate-cortisol. The personality trait is closeness to experiences to maintain tradition.

The mental immune system regulator is serotonin-GABA (gamma amino butyric acid) agonist to balance adrenaline-glutamate-cortisol. Excessive unfamiliarity-uncertainty and phobia in the inherited highly imbalanced system without proper serotonin-GABA agonist generate overactive phobia-stress as the overactive mental immune system, resulting in the mental allergy as fearful-anxious cluster in personality disorders against ubiquitous unfamiliarity-uncertainty as shown by deficient serotonin-GABA. In terms of neurotransmitters, the failure of constraining adrenaline-glutamate-cortisol (phobia-stress) by serotonin and GABA agonist as the mental immune system regulator results in the mental allergy as fearful-anxious cluster. The symptoms are overactive phobia, ubiquitous perceived unfamiliarity-uncertainty, and all-or-nothing thinking without nuance in dealing with unfamiliarity-uncertainty. Fearful-anxious cluster personality disorders include dependent, avoidant, and obsessive-compulsive. For dependent, the overactive phobia is inoffensive (agreeableness). For obsessive-compulsive, the overactive phobia is offensive (disagreeableness). For avoidant, the overactive phobia is territorial. Overactive phobia-stress is more extreme in mental disorders than in personality disorders. PTSD (post trauma stress disorder) mental disorder is due to the complete breakdown of familiarity and certainty in extreme trauma-stress, such as battle. 


\subsection{The Phobia-Rationality-Indecision Axis and Doubtful-Prying Cluster}

As the deviation from familiar-certain traditional way of life, unfamiliarity-uncertainty as the adversity brings about instinctive phobia, but instead of staying away from unfamiliarity-uncertainty, rationality detached from emotion is used to open to and to adapt to unfamiliarity-uncertainty. Rationality instead of phobia is the mental countermeasure to overcome unfamiliarity-uncertainty. Under rationality detached from emotion, unfamiliarity-uncertainty turns into inconsistency-opacity which can be dealt with rationally. Rationality is followed by indecision to focus in inconsistency-opacity without the emotion to make the final decision. The purpose of the phobia-rationality-indecision is to maintain adaptability. Without emotion, the phobia-rationality-indecision has adrenaline-glutamate without cortisol. The mental immune system against unfamiliarity-uncertainty is the phobia-rationality-indecision axis with adrenaline-glutamate. Rationality detached from emotion is logical, consistent, demonstrable, factual, and provable. Rationality is found in the frontal lobe of the neocortex for the rational brain. The personality trait is openness to experience to maintain adaptability.

The mental immune system regulator is GABA agonist to balance glutamate. Excessive unfamiliarity-uncertainty and rationality in the inherited highly imbalanced system without proper GABA agonist generate the overactive phobia-rationality-indecision axis as the overactive mental immune system, resulting in the mental allergy as doubtful-prying cluster in personality disorders against ubiquitous inconsistency-opacity as shown by deficient GABA. In terms of neurotransmitters, the failure of constraining adrenaline-glutamate (phobia-rationality-indecision) by GABA agonist as the mental immune system regulator results in the mental allergy as doubtful-prying cluster. The symptoms of doubtful-prying are overactive rationality, ubiquitous perceived inconsistency-opacity, and all-or-nothing thinking without nuance in dealing with inconsistency-opacity. Doubtful-prying cluster personality disorders include anarchic, quarrelsome, and evasive. For anarchic, the overactive rationality is inoffensive (agreeableness). For quarrelsome, the overactive rationality is offensive (disagreeableness). For evasive, the overactive rationality is territorial. For the highly rational professional psychologists who published the DSM-5, doubtful-prying was not considered as personality disorder.

\subsection{The Religious Mental Immune System}

The main concern of the Abrahamic religions (Judaism, Christianity, and Islam), Buddhism, and Daoism is adversity, so they build the religious mental immune system against adversity in the same structure as the mental immune system consisting of the four mental immune systems with the four immune system regulator as in Table 4.

For the Abrahamic religions, the divine love is the religious comforter as the 
Table 4. The religious mental immune system.

\begin{tabular}{|c|c|c|c|c|}
\hline Adversity & $\begin{array}{l}\text { Mental } \\
\text { countermeasure }\end{array}$ & Religion & Religious mental countermeasure & $\begin{array}{l}\text { Religious mental immune system } \\
\text { regulator }\end{array}$ \\
\hline \multirow{3}{*}{ Hardship } & \multirow{3}{*}{ Comforter } & Abrahamic religions & Divine love & Divine providence \\
\hline & & Buddhism & Universal compassion & Cessation of desire \\
\hline & & Daoism & Balanced hardship-fortune & Balanced fortune-hardship \\
\hline \multirow{3}{*}{ Danger } & \multirow{3}{*}{ Hyperactivity } & Abrahamic religions & Divine miraculous salvation & Divine providence \\
\hline & & Buddhism & nirvana & Cessation of desire \\
\hline & & Daoism & Balanced danger-fortune & Balanced fortune-danger \\
\hline $\begin{array}{l}\text { Unfamiliarity- } \\
\text { uncertainty }\end{array}$ & Phobia & Abrahamic religions & Divine authority & Divine providence \\
\hline \multirow{2}{*}{$\begin{array}{l}\text { Unfamiliarity- } \\
\text { uncertainty }\end{array}$} & \multirow{2}{*}{ Rationality } & Buddhism & Rational impermanence & Acceptance of the unknown \\
\hline & & Daoism & Rational adaptation & Acceptance of the unknown \\
\hline
\end{tabular}

countermeasure against hardship. The divine providence to deal with hardship is the religious mental immune system regulator. The divine love is regulated by the divine providence (wisdom) that knows the best time and the best way to provide the divine love. God is always inexplicably in control regardless of prevailing hardship. Believing in the divine providence, a believer in the divine love looks beyond prevailing hardship to the coming of the divine love, resulting in the elimination of the overactive religious mental immune system against ubiquitous perceived hardship. The divine miraculous salvation is the religious hyperactivity as the countermeasure against danger. The divine providence to deal with danger is the religious mental immune system regulator. The divine miraculous salvation is regulated by divine providence that knows the best time and the best way to provide divine miraculous salvation. God is always inexplicably in control regardless of prevailing danger. Believing in the divine providence, a believer in the divine salvation looks beyond prevailing danger to the coming of the divine salvation, resulting in the elimination of the overactive religious mental immune system against ubiquitous perceived danger. The divine authority that is the ultimate authority in power, laws, and traditions provides the phobia as the religious mental countermeasure against moving to unfamiliar-uncertain way of life (sins) as the deviation from the divine authority. To obtain the peace of mind away from fear and anxiety, a believer must follow the divine authority. The divine providence in dealing with unfamiliarity-uncertainty is the religious immune system regulator. The divine authority is regulated by the divine providence that knows the best time and the best way to deal with unfamiliarity-uncertainty as the deviation from the divine authority. God is always mysteriously in control regardless of prevailing sins. Believing in the divine providence, a believer in the divine authority looks beyond prevailing unfamiliarity-uncertainty (sins) to the coming of the divine authority, resulting in the elimination of the overactive religious mental immune system against ubiquitous perceived unfamiliarity-uncertainty. For the Abrahamic religions, God is the divine love against hardship, the divine miraculous salvation against danger, the divine authority against unfamiliarity-uncertainty, and is regulated by the divine 
providence.

For Buddhism, the universal compassion is the religious mental countermeasure against hardship. The cessation of desire is the religious mental immune system regulator. The universal compassion is regulated by the cessation of desire to stop constantly seeking comforter. The cessation of desire functions as dopamine (pleasure neurotransmitter) antagonist. The cessation of desire is obtained by meditation. Nirvana to be achieved through high diligent effort is the religious mental countermeasure as the ultimate happiness to overcome dangerous suffering life in terms of endless reincarnation. The cessation of desire is the religious mental immune system regulator, because nirvana is literally means "blown out" as in an oil lamp, and is the realization of non-self and emptiness, which can be achieved by the cease of desire. The cessation of desire functions as serotonin (control neurotransmitter) agonist. The cessation of desire is obtained by meditation. Impermanence is the religious mental countermeasure as rationality against unfamiliarity-uncertainty. Life is impermanent full of unfamiliarity and uncertainty. Impermanence as the rational explanation about unfamiliarity-uncertainty removes fear and anxiety about unfamiliarity-uncertainty. The acceptance of the unknown is the religious mental immune system regulator. The unknown is the end of all impermanence. Buddha refused to speculate about gods and afterlife which simply constitute the unknown part of impermanence. For Buddhism, the mental immunity system is the universal compassion against hardship, nirvana against danger, and rational impermanence against unfamiliarity-uncertainty, and is regulated by the cease of desire, the cease of desire, and the acceptance of the unknown, respectively.

Daoism is basically about balance such as the balance between yin and yang [31]. A most important balance is the balanced adversity-fortune. Whenever one thinks too much about adversity, think about possible fortune after adversity. Equally, whenever one thinks too much about fortune, thinks about possible adversity after fortune. As a result, the balanced hardship-fortune, balanced danger-fortune, and other types of balances constitute the balanced mental immune systems. The first chapter of the Book of Mean from Confucianism describes how to deal with emotion, "When joy, anger, sorrow and pleasure have not yet arisen, it is the state of equilibrium. When they arise to their appropriate levels, it is the state of harmony. The state of equilibrium is the great base of all-under heaven. The state of harmony is the universal path to be pursued. When the states of equilibrium and harmony are actualized, Heaven and Earth are in their proper positions, and all things are nourished." The goals of the balance in the balanced religious immune systems are to reach the states of equilibrium without arising emotion and the state of harmony with arising emotion. For Daoism, adaptation is the religious mental countermeasure as rationality to overcome unfamiliarity-uncertainty. Rational adaptation to unfamiliarity-uncertainty removes fear and anxiety about unfamiliarity-uncertainty. For Daoism, the symbol of adaptation is water which can flow over anywhere regardless of environmen- 
tal shapes. In the Chapter 8 of Dao De Jing, Supreme good is like water. Water greatly benefits all things, without conflict. It flows through places that people loathe. Thereby it is close to the Way. The acceptance of the unknown is the religious mental immune system regulator. For Daoism, the origin of everything is the nameless (unknown) in the first chapter of Dao De Jing. The religious mental immune system by Daoism is essentially same as the natural mental immune system through the balances to the appropriate levels.

\subsection{Drug Addiction Disorders}

Drug addictions [32] are derived from the self-administered mental countermeasures against perceived adversities in terms of hardship, danger, and unfamiliarity-uncertainty. The self-administered mental countermeasure as comforter against perceived hardship includes opioids (heroin, codeine, morphine, fentanyl, hydrocodone, oxycodone, buprenorphine, and methadone), hallucinogens (psilocybin, lysergic acid diethylamide, peyote, and dimethyltryptamine), cannabis (marijuana, hashish, and hash oil), inhalants (volatile organic solvents), nicotine, and alcohol. The self-administered mental countermeasures as hyperactivity and phobia against perceived danger and unfamiliarity-uncertainty include stimulants (cocaine, crack cocaine, amphetamine, and methamphetamine), nicotine, and alcohol. The self-administered mental immune system regulator to the phobia-stress axis includes depressants (barbiturates and benzodiazepines) and alcohol which are also addictive dopamine agonists. The self-administered countermeasures are prone to generate overactive stress-countermeasures as overactive mental immune systems, resulting in the mental allergies as drug addiction disorders against increasingly more ubiquitous perceived adversities to be overcome by increasingly stronger addicted drugs. A reason for self-administered mental countermeasures is likely the need of a person with psychiatric disorder against ubiquitous perceived adversity. Self-administered mental countermeasure generates drug addiction disorder which enhances the severity of psychiatric disorder, resulting in the comorbidity of drug addiction disorder and psychiatric disorder.

\subsection{Psychiatric Epidemiology}

Psychiatric epidemiology studies the causes and the prevalence of psychiatric disorders in society. Psychiatric disorders are derived from genetic factor and environmental factor. A meta-analysis of twin-studies found a combined heritability of $46 \%$ for psychiatric disorders [33]. According the report by the World Health Organization in 2001, about one in four people in the world meet the criteria of psychiatric disorders at some point in their life [34]. In all societies in the world throughout the history [35], psychiatric disorders have existed, indicating some useful social function of psychiatric disorders. In fact, in ancient time, psychiatric disorders were sometimes thought to represent supernatural agents, sorcery, or witchcraft. In normal society with infrequent adversity, com- 
plex social interactions, and moderate emotional expression, psychiatric disorders that produce ubiquitous perceived adversity, all-or-nothing thinking, and overactive mental countermeasures (comforter, hyperactivity, and phobia) are considered to be maladaptive and disruptive. On the other hand, under abnormal society with frequent adversity, polarization, and strong social outcry, psychiatric disorders that produce ubiquitous perceived adversity, all-or-nothing thinking, and overactive mental countermeasures become adaptive and foresighted. In abnormal society, odd-eccentric leaders become visionary leaders to lead people in hardship to new direction, dramatic-impulsive leaders become heroic leaders to rescue people in danger, fearful-anxious leaders become patriotic leaders to save fearful people from losing familiar-certain tradition, and doubtful-prying leaders become top scientists to guide doubtful people to expose and explore inconsistency-opacity. Therefore, psychiatric disorders have the useful social function in abnormal society to save abnormal society from extinction. However, psychiatric disorders confuse real and false adversities, ignore complex social interactions, and disregard calm dialogues, resulting in the failure of the transition from abnormal society to new normal society. Since during the human evolution, normal society occurs more often than abnormal society, the social preference to the people without psychiatric disorders over the people with psychiatric disorders in normal society results in more genes without psychiatric disorders than genes with psychiatric disorders. Consequently, normal genes prevail over abnormal genes to form the normal majority.

\subsection{The Convictive Cognitive Regulative Behavior Therapy}

The four important methods of psychotherapy are psychoanalysis, the cognitive behavioral therapy, the meditational therapy, and the medication therapy. The combination of the four therapies is the convictive cognitive regulative behavioral therapy (CCRT) consisting of conviction in psychoanalysis, cognition in the cognitive behavioral therapy, and behavioral regulation (the mental immune system regulator) in the meditational-medication therapies. The convictive behavioral therapy is psychoanalysis [36] which finds and differentiates the proper and improper convictions (firm beliefs). The proper conviction as the guide for lifelong behaviors is culturally acceptable, community-based, and workable conviction, whereas the improper conviction as the misguidance for lifelong behaviors is culturally unacceptable, egotistic, and unworkable conviction. Pre-conviction is id consisting of instincts. Conviction is ego to guide lifelong behaviors, and ego can be a proper or improper conviction. Proper conviction is super-ego as culturally acceptable, community-based, and workable conviction. The ego with improper conviction is suppressed by super-ego which has proper conviction. The purposes of psychoanalysis are to find a rational and adaptive way to deal with suppressed ego that has improper conviction, and to provide a strong proper conviction to guide lifelong behaviors.

It is important to have a strong and proper conviction to guide lifelong beha- 
viors. It is also important to have the proper cognition to guide daily specific behaviors. The cognitive behavioral therapy [37] deals with conscious cognition instead of conviction as in psychoanalysis. The cognitive behavioral therapy finds and differentiates the proper and improper conscious cognitions. The proper cognition (thought) is rational, positive, and adaptive. With overactive perception in adversity and overactive emotion to deal with adversity, the improper cognition is irrational, negative, and maladaptive. The therapy deals with the identification of improper cognition and the formulation of a proper cognition which is more rational, realistic, and balanced in interpreting one's reality. The cognitive behavioral therapy replaces improper cognition with proper cognition, and links proper cognition with proper behaviors.

The regulative behavioral therapy provides the behavioral mental immune system regulator to constrain the overactive mental immune system. The methods in the regulative behavioral therapy are meditation [38] and medication [39]. Meditations simply have the opposite responses from the mental immune responses. The opposites of comforter response, hyperactivity response, and phobia response in the mental immune system are neutral nonjudgmental responses in the meditations including nonjudgmental mindfulness meditation with open-focus and concentration meditation with focus. The regulative behaviors learned from the meditational responses in the daily meditations provide the patterns of the mental immune system regulator to regulate the mental immune system against perceived adversities. The medication therapy consists of essentially the mental immune system regulators. One can think of a meditation as a behavioral Prozac. The therapy for personality-mental disorders requires strong proper conviction to guide lifelong behaviors, rational proper cognition to guide daily behaviors, and regulative meditation-medication to constrain comforter, hyperactivity, phobia, and rationality.

\subsection{The Big Five Mental Protection Traits, the Big Five Social System Traits, and the Big Five Personality Traits}

The mental protection system correlates to the big five social system traits and the big five personality traits as described in the previous paper [6]. The big five protections from the mental protection system are the social member protection (individualistic-collectivistic-interdependent socialities), the social function protection (territorial-connective-competitive worldviews), the hardship protection (balanced-imbalanced), the danger protection (balanced-imbalanced), and the unfamiliarity-uncertainty protection (phobia-rationality). The big five social system traits [6] are the fixed, clear, and workable social solutions to the social issues under the different social conditions. The big five social system issues consist of social formation (individualistic-collectivistic-interdependent sociality social system traits), social boundary (territorial-connective-competitive world view social system traits), social stress (concrete-imaginary awareness social system traits), social duration (constructional-mobilized activity social system 
traits), and social uniformity (authoritative-rational legitimacy social system traits).

The social member protection (individualistic-collectivistic-interdependent sociality) corresponds to social formation (individualistic-collectivistic-interdependent socialities). The social function protection (territorial-connectivecompetitive worldviews) corresponds to social boundary (territorial-connectivecompetitive worldviews). The hardship protection (balanced-imbalanced) corresponds to social stress as hardship. The balanced protection correlates to concrete awareness in stress-free social system, while the moderately imbalanced protection correlates to imaginary awareness for excessive imaginary comforter in stressful social system. The danger protection (balanced-imbalanced) corresponds to social duration as the degree of danger. The balanced protection correlates to constructional activity in long durable social system, whereas the moderately imbalanced protection correlates to mobilized activity for excessive hyperactivity in transient unstable social system. The unfamiliarity-uncertainty protection (phobia-rationality) corresponds to social uniformity as the degree of unfamiliarity-uncertainty, Phobia to avoid unfamiliarity-uncertainty is suitable in homogeneous social system with the high degree of social uniformity (the low degree of unfamiliarity-uncertainty), whereas rationality to adapt to unfamiliarity-uncertainty is suitable for diverse social system with the low degree of social uniformity (the high degree of unfamiliarity-uncertainty). The big five protections also correlate to the big five personality traits as described in the previous sections. The big five mental protection traits, the big five social system traits, and the big five personality traits are described in Table 5.

\section{Summary and Conclusion}

In summary, this paper proposes that the mental protection system of body consists of the social brain to set up the protective social groups for vulnerable social members-functions and the mental immune system to produce the mental

Table 5. The big five mental protection traits, the big five social system traits, and the big five personality traits.

\begin{tabular}{|c|c|c|c|c|c|}
\hline $\begin{array}{l}\text { Big five mental } \\
\text { protection traits }\end{array}$ & Trait components & $\begin{array}{l}\text { Big five social } \\
\text { system issues }\end{array}$ & $\begin{array}{l}\text { Big five social } \\
\text { system traits }\end{array}$ & $\begin{array}{l}\text { Trait } \\
\text { components }\end{array}$ & $\begin{array}{l}\text { Big five } \\
\text { personality traits }\end{array}$ \\
\hline Social member protection & $\begin{array}{l}\text { Individualistic sociality } \\
\text { Collectivistic sociality } \\
\text { Interdependent sociality }\end{array}$ & Social formation & Sociality & $\begin{array}{l}\text { Individualistic } \\
\text { Collectivistic } \\
\text { Interdependent }\end{array}$ & $\begin{array}{l}\text { Extraversion } \\
\text { Introversion } \\
\text { Interdependence }\end{array}$ \\
\hline Social function protection & $\begin{array}{l}\text { Territorial worldview } \\
\text { Connective worldview } \\
\text { Competitive worldview }\end{array}$ & Social boundary & Worldview & $\begin{array}{l}\text { Territorial } \\
\text { Connective } \\
\text { Competitive }\end{array}$ & $\begin{array}{l}\text { Territoriality } \\
\text { Agreeableness } \\
\text { Disagreeableness }\end{array}$ \\
\hline Hardship protection & $\begin{array}{l}\text { Balanced stress-comforter axis } \\
\text { Imbalanced stress-comforter axis }\end{array}$ & Social stress & Awareness & $\begin{array}{l}\text { Concrete } \\
\text { Imaginary }\end{array}$ & $\begin{array}{l}\text { Calmness } \\
\text { Neuroticism }\end{array}$ \\
\hline Danger protection & $\begin{array}{l}\text { Balanced hyperactivity-stress axis } \\
\text { Imbalanced hyperactivity-stress axis }\end{array}$ & Social duration & Activity & $\begin{array}{l}\text { Constructional } \\
\text { Mobilized }\end{array}$ & $\begin{array}{l}\text { Conscientiousness } \\
\text { Impulsiveness }\end{array}$ \\
\hline $\begin{array}{l}\text { Unfamiliarity-uncertainty } \\
\text { protection }\end{array}$ & $\begin{array}{l}\text { Phobia-stress axis } \\
\text { Phobia-rationality-indecision axis }\end{array}$ & Social uniformity & Legitimacy & $\begin{array}{l}\text { Authoritarian } \\
\text { Rational }\end{array}$ & $\begin{array}{l}\text { Closeness } \\
\text { Openness }\end{array}$ \\
\hline
\end{tabular}


protective countermeasures against adversities, corresponding to the physical protection system of the body consisting of the integumentary system to set up the protective organs for vulnerable body parts-functions and the immune system to produce the protective countermeasures against harmful invaders (pathogens). The protective social groups from the social brain include individualistic alliance group to protect vulnerable individuals, collectivistic kinship-friendship group to protect vulnerable children, interdependent specialists group to protect vulnerable pregnant females, territorial group to protect social boundary between ingroup and outgroup, connective group to protect social connection, and competitive group to protect social competition. The social moralities, social organizations, and cultures can be derived from the protective social groups.

The mental protective countermeasures from the mental immune system include comforter in the stress-comforter axis against hardship to maintain durability, hyperactivity in the hyperactivity-stress axis against danger to maintain existence, phobia in the phobia-stress axis against unfamiliarity-uncertainty to maintain tradition, and rationality in the phobia-rationality-indecision axis against unfamiliarity-uncertainty to maintain adaptability. In the inherited highly imbalanced mental immune system without the balance by the mental immune system regulator, the overactive mental immune system produces mental allergies and mental autoimmune disorders as personality-mental disorders against ubiquitous perceived adversity, corresponding to the overactive immune system producing physical allergies and physical autoimmune diseases against ubiquitous detected harmful and harmless invaders. Personality disorders are divided into odd-eccentric cluster from the overactive stress-comforter axis against ubiquitous perceived hardship, dramatic-impulsive cluster from the overactive hyperactivity-stress axis against ubiquitous perceived danger, fearfulanxious cluster from the overactive phobia-stress axis against ubiquitous perceived unfamiliarity-uncertainty, and doubtful-prying from the overactive phobia-rationality-indecision axis against ubiquitous perceived unfamiliarity-uncertainty.

The combination of the religions and the mental immune system is the religious immune system with its religious immune system regulators. Drug addictions are derived from the self-administered mental countermeasures against perceived adversities in terms of hardship, danger, and unfamiliarity-uncertainty. Psychiatric epidemiology indicates some useful social function of psychiatric disorders, but the normal majority still prevails. The therapy of personality-mental disorders consists of conviction in psychoanalysis, cognition in the cognitive behavioral therapy, and behavioral regulation (the mental immune system regulator) in the meditational-medication therapies, resulting in the convictive cognitive regulative behavioral therapy (CCRT). The therapy for personality-mental disorders requires strong proper conviction to guide lifelong behaviors, rational proper cognition to guide daily behaviors, and regulative medi- 
tation-medication to constrain comforter, hyperactivity, phobia, and rationality. The five big mental protection traits from the mental protection system correlate to the big five social system traits, and the big five personality traits.

In conclusion, the mental protection system consisting of the social brain and the mental immune system sets up the protective social groups and the protective mental countermeasures to produce protective behaviors, relating to personality traits, social moralities, social organizations, social systems, religions, cultures, and personality-mental disorders as described in this paper. The future study will focus on how the mental protection system develops hormonally, physically, psychologically, and socially during different stages of life.

\section{References}

[1] Dunbar, R. (2009) The Social Brain Hypothesis and Its Implications for Social Evolution. Annals of Human Biology, 36, 562-572. https://doi.org/10.1080/03014460902960289

[2] Dunbar, R. (2016) The Social Brain Hypothesis and Human Evolution. Oxford Research Encyclopedia of Psychology, Online Publication. https://doi.org/10.1093/acrefore/9780190236557.013.44

[3] Frith, C. (2007) The Social Brain? Philosophical Transactions of the Royal Society B: Biological Sciences, 362, 671-678. https://doi.org/10.1098/rstb.2006.2003

[4] Cozolino, L. (2006) The Neuroscience of Human Relationships: Attachment and the Developing Social Brain. W. W. Norton \& Co., New York.

[5] Chung, D. (2017) Human Cultural Evolution: Postmodernity as Rational Global Diversity. Open Journal of Social Sciences, 5, 304-337. https://doi.org/10.4236/jss.2017.55022

[6] Chung, D. (2017) The Big Five Social System Traits as the Source of Personality Traits, MBTI, Social Styles, Personality Disorders, and Cultures. Open Journal of Social Sciences, 5, 269-295. https://doi.org/10.4236/jss.2017.59019

[7] Leonard, B.E. (2010) The Concept of Depression as a Dysfunction of the Immune System. Current Immunology Reviews, 6, 205-212. https://doi.org/10.2174/157339510791823835

[8] Goldberg, L. (1993) The Structure of Phenotypic Personality Traits. American Psychologist, 48, 26-34. https://doi.org/10.1037/0003-066X.48.1.26

[9] Shultz, S. and Dunbar, R. (2007) The Evolution of the Social Brain: Anthropoid Primates Contrast with Other Vertebrates. Proceeding of Royal Society B, 274, 2429-2436. https://doi.org/10.1098/rspb.2007.0693

[10] Crespi, B.J. and Douglas, Y. (1995) The Definition of Eusociality. Behavior Ecology, 6, 109-115. https://doi.org/10.1093/beheco/6.1.109

[11] Fonagy, P., Gergely, G., Jurist, E. and Target, M. (2002) Affect Regulation, Mentalization and the Development of the Self. Other Press, New York.

[12] Dunbar, R. (1993) Coevolution of Neocortex Size, Group Size and Language in Humans. Behavioral and Brain Sciences, 16, 681-735. https://doi.org/10.1017/S0140525X00032325

[13] Kennedy, D. and Adolphs, R. (2012) The Social Brain in Psychiatric and Neurological Disorders. Trends in Cognitive Sciences, 16, 559-572.

https://doi.org/10.1016/j.tics.2012.09.006 
[14] Hamilton, W. (1964) The Genetical Evolution of Social Behavior II. Journal of Theoretical Biology, 7, 17-52. https://doi.org/10.1016/0022-5193(64)90039-6

[15] Yang, H.P., Wang, L., Han, L. and Wang, S. (2013) Nonsocial Functions of Hypothalamic Oxytocin. ISRN Neuroscience, 2013, Article ID: 179272. https://doi.org/10.1155/2013/179272

[16] Wilson, E.O. (2012) The Social Conquest of the Earth. W. W. Norton \& Company, New York.

[17] Chung, D. (2016) The Basic Principles of Kin Sociality and Eusociality: Human Evolution. Natural Science, 8, 8-19. https://doi.org/10.4236/ns.2016.81002

[18] White, T.D., et al. (2009) Ardipithecusramidus and the Paleobiology of Early Hominins. Science, 326, 75-86. https://doi.org/10.1126/science.1175802

[19] Adenzato, M., et al. (2010) Theory of Mind Ability in the Behavioral Variant of Frontotemporal Dementia: An Analysis of the Neural, Cognitive, and Social Levels. Neuropsychologia, 48, 2-12. https://doi.org/10.1016/j.neuropsychologia.2009.08.001

[20] Turner, J.C. and Reynolds, K.J. (2010) The Story of Social Identity. In: Postmes, T. and Branscombe, N., Eds., Rediscovering Social Identity: Core Sources, Psychology Press, New York.

[21] Cohen, T., Montoya, R. and Insko, C. (2006) Group Morality and Intergroup Relations: Cross-Cultural and Experimental Evidence. Personality and Social Psychology Bulletin, 32, 1559-1572. https://doi.org/10.1177/0146167206291673

[22] Hamlin, J.K., Mahajan, N. and Wynn, K. (2013) Not Like Me = Bad Infants Prefer Those Who Harm Dissimilar Others. Psychological Science, 24, 589-594. https://doi.org/10.1177/0956797612457785

[23] Shultz, T., Hartshorn, M. and Kaznatcheev, A. (2009) Why Is Ethnocentrism More Common than Humanitarianism? In: Taatgen, N.A. and Rijn, H.V., Eds., Proceedings of the 31 st Annual Conference of the Cognitive Science Society, Cognitive Science Society, Austin, 2100-2105.

[24] Nisbett, R. (2004) The Geography of Thought: How Asians and Westerners Think Differently ... and Why. Free Press, New York.

[25] Yuki, M., et al. (2005) Cross-Cultural Differences in Relationship- and Group-Based Trust. Personality and Social Psychology Bulletin, 31, 48-62. https://doi.org/10.1177/0146167204271305

[26] American Psychiatric Association (2013) Diagnostic and Statistical Manual of Mental Disorders. 5th Edition, American Psychiatric Publishing, Arlington.

[27] Boecker, H., et al. (2008) The Runner's High: Opioidergic Mechanisms in the Human Brain. Cerebral Cortex, 18, 2523-2531. https://doi.org/10.1093/cercor/bhn013

[28] Taylor, M. (1999) Imaginary Companions and the Children Who Create Them. Oxford University Press, New York.

[29] Taylor, M., Hulette, A. and Dishion, T. (2010) Longitudinal Outcomes of Young High-Risk Adolescents with Imaginary Companions. Developmental Psychology, 46, 1632-1636. https://doi.org/10.1037/a0019815

[30] Feusner, J., Townsend, J., Bystritsky, A. and Bookheimer, S. (2007) Visual Information Processing of Faces in Body Dysmorphic Disorder. Archives of General Psychiatry, 64, 1417-1425. https://doi.org/10.1001/archpsyc.64.12.1417

[31] Komjathy, L. (2014) Daoism: A Guide for the Perplexed. Bloomsbury Academic, New York.

[32] Brick, J. and Erickson, C. (2012) Drugs, the Brain, and Behavior: The Pharmacology of Drug Use Disorders. Routledge, New York. 
[33] Polderman, T., et al. (2015) Meta-Analysis of the Heritability of Human Traits Based on Fifty Years of Twin Studies. Nature Genetics, 47, 702-709. https://doi.org/10.1038/ng.3285

[34] WHO International Consortium in Psychiatric Epidemiology (2000) Cross-National Comparisons of the Prevalences and Correlates of Mental Disorders. Bulletin of the World Health Organization, 78, 413-426.

[35] Hinshaw, S.P. (2007) The Mark of Shame: Stigma of Mental Illness and an Agenda for Change. Oxford University Press, Oxford.

[36] Arlow, J. (1991) Psychoanalysis: Clinical Theory and Practice. International Universities Press, Madison.

[37] Kazantzis, N., Reinecke, M. and Freeman, A. (2010) Cognitive and Behavioral Theories in Clinical Practice. Guilford, New York.

[38] Simpkins, A. and Simpkins, C. (2016) Core Principles of Meditation for Therapy: Improving the Outcomes for Psychotherapeutic Treatments. John Wiley \& Sons, Inc., New York.

[39] Shaywitz, J. and Marder, S. (2011) Medication Treatment for Anxiety, Depression, Schizophrenia, and Bipolar Disorder in the Community Setting. Oxford University Press, New York. 